Research Paper

\title{
Gestational Hypoxia Up-regulates Protein Kinase $C$ and Inhibits Calcium-Activated Potassium Channels in Ovine Uterine Arteries
}

\author{
Daliao Xiao, Ronghui Zhu, and Lubo Zhang ${ }^{凶}$ \\ Center for Perinatal Biology, Division of Pharmacology, Department of Basic Sciences, Loma Linda University School of Medicine, Loma \\ Linda, CA, USA
}

\begin{abstract}
$\square$ Corresponding author: Lubo Zhang, Ph.D. Center for Perinatal Biology, Department of Basic Sciences, Loma Linda University, School of Medicine, Loma Linda, CA 92350. Tel: 909-558-4325; Fax: 909-558-4029; Email: lzhang@llu.edu

(C) Ivyspring International Publisher. This is an open-access article distributed under the terms of the Creative Commons License (http://creativecommons.org/ licenses/by-nc-nd/3.0/). Reproduction is permitted for personal, noncommercial use, provided that the article is in whole, unmodified, and properly cited.
\end{abstract}

Received: 2014.04.08; Accepted: 2014.06.0I; Published: 20I4.06.20

\begin{abstract}
Objective: The present study tested the hypothesis that gestational hypoxia up-regulates protein kinase $\mathrm{C}(\mathrm{PKC})$ and inhibits calcium-activated potassium channels $\left(\mathrm{K}_{\mathrm{C}_{\mathrm{a}}}\right)$-mediated relaxations of uterine arteries in pregnancy. Study design: Uterine arteries were isolated from nonpregnant (NPUA) and pregnant (PUA) ( 140 day gestation) sheep maintained at either sea level or high altitude $\left(3,820 \mathrm{~m}\right.$ for 110 days, $\left.\mathrm{PaO}_{2}: 60 \mathrm{mmHg}\right)$. Contractions of uterine arteries were determined. Key findings: In normoxic PUA, selective inhibition of large-conductance $K_{C a}(B K)$ channels significantly enhanced PKC activator phorbol 12, 13-dibutyrate (PDBu)-induced contractions. This effect was abrogated by chronic hypoxia in gestation. Unlike BK channels, inhibition of small-conductance $\mathrm{K}_{\mathrm{Ca}_{\mathrm{a}}}(\mathrm{SK})$ channels had no significant effect on PDBu-mediated contractions. In normoxic PUA, activation of both BK with NSI619 or SK with NS309 produced concentration-dependent relaxations, which were not altered by the addition of PDBu. However, in uterine arteries treated with chronic hypoxia $\left(10.5 \% \mathrm{O}_{2}\right.$ for $\left.48 \mathrm{~h}\right)$, both NSI619- and NS309-induced relaxations were significantly attenuated by PDBu. In NPUAs, inhibition of BK channels significantly enhanced PDBu-induced contractions in both normoxic and hypoxic animals. Conclusion: The results suggest that in the normoxic condition BK inhibits PKC activity and uterine vascular contractility, which is selectively attenuated by chronic hypoxia during gestation. In addition, hypoxia induces PKC-mediated inhibition of BK and SK activities and relaxations of uterine arteries in pregnancy.
\end{abstract}

Key words: chronic hypoxia, pregnancy, $\mathrm{PKC}, \mathrm{K}^{+}$channel, uterine arterial contractility.

\section{Introduction}

Chronic hypoxia during gestation significantly increases the incidences of preeclampsia and fetal intrauterine growth restriction (IUGR) [1-8]. However, the mechanisms underlying hypoxia-induced adverse pregnancy outcomes are largely unknown. Previous studies suggested that hypoxia-induced aberration of uteroplacental circulation in pregnancy was important in pathogenesis of many pregnancy complications [5,8-12]. Indeed, chronic hypoxia during gestation has profound adverse effects on uterine ar- tery contractility and significantly increases uterine vascular tone, leading to attenuation of pregnancy-induced increase in uterine blood flow and increased risk of IUGR and preeclampsia [1,12-14].

The molecular mechanisms underlying the adaptation of uterine arterial contractility to normal pregnancy and chronic hypoxia are complex and remain poorly understood. Pregnancy is characterized by an increase in uterine vascular relaxation and a decrease in uterine arterial constriction and vascular 
tone. Recent studies have demonstrated that pregnancy-induced decrease in uterine vascular tone is mediated by an increase in $\mathrm{Ca}^{2+}$-activated $\mathrm{K}^{+}\left(\mathrm{K}_{\mathrm{Ca}}\right)$ channel expression and activity $[3,15]$. Inhibition of $\mathrm{K}_{\mathrm{Ca}}$ channels reversed the pregnancy-mediated decrease in uterine vascular myogenic tone and increase in uterine blood flow [15-17], suggesting that enhanced $\mathrm{K}_{\mathrm{Ca}}$ channel function plays an important role in the adaptation of uterine circulation during pregnancy. Chronic hypoxia during gestation inhibited pregnancy-induced attenuation of uterine vascular tone via suppressing $\mathrm{K}_{\mathrm{Ca}}$ channel function $[3,18]$. These studies demonstrated a mechanism of $\mathrm{K}_{\mathrm{Ca}}$ channels in regulating myogenic adaption of uterine arteries in pregnancy as well as in maladaptation of uterine circulation caused by chronic hypoxia during gestation.

In contrast to $\mathrm{K}_{\mathrm{Ca}}$ channels that are up-regulated by pregnancy and down-regulated by chronic hypoxia, the activity of protein kinase $\mathrm{C}$ (PKC) and its mediation of uterine vascular contraction are down-regulated by pregnancy and up-regulated by chronic hypoxia [19-22]. Thus, pregnancy and chronic hypoxia differentially regulate $\mathrm{K}_{\mathrm{Ca}}$ channel function and PKC activities in uterine arteries. The balance between activations of $\mathrm{K}_{\mathrm{Ca}}$ channels and PKC is likely to play an important role in the adaptation of uterine vascular tone to pregnancy and chronic hypoxia. However, the interaction between $\mathrm{K}_{\mathrm{Ca}}$ channels and PKC as well as how they orchestrate and integrate to regulate uterine vascular contractility during pregnancy in response to chronic hypoxia remain largely unknown.

The goal of the present study is to investigate the potential effect of $\mathrm{K}_{\mathrm{Ca}}$ channel inhibitors on PKC-mediated uterine arterial contractions in nonpregnant and pregnant sheep that reside in normoxic sea levels or exposed to long-term high altitude hypoxia. To further determine the interaction of PKC and $\mathrm{K}_{\mathrm{Ca}}$ channel function and the effect of pregnancy and chronic hypoxia, we also investigated the effect of PKC activation on $\mathrm{K}_{\mathrm{Ca}}$ channel-mediated relaxations of uterine arteries in nonpregnant and pregnant ewes in the normoxic and hypoxic conditions.

\section{Materials and Methods}

\section{Tissue preparation and treatment}

All procedures and protocols used in the present study were approved by the Animal Research Committee of Loma Linda University and followed the guidelines by the National Institutes of Health Guide for the Care and Use of Laboratory Animals. As previously described [2], nonpregnant and time-dated pregnant sheep were obtained from the Nebeker
Ranch in Lancaster, CA (altitude: $\sim 300 \mathrm{~m}$; arterial $\mathrm{PaO}_{2}: 102 \pm 2 \mathrm{mmHg}$ ). For chronic hypoxic treatment, nonpregnant and pregnant (30 days of gestation) animals were transported to the Barcroft Laboratory, White Mountain Research Station, Bishop, CA (altitude, 3,820 m; maternal $\mathrm{PaO}_{2}, 60 \pm 2 \mathrm{mmHg}$ ) and maintained there for $\sim 110$ days. After hypoxic treatment, the animals were transported to the laboratory immediately. Animals were anesthetized with ketamine $(10 \mathrm{mg} / \mathrm{kg}$, iv), followed by incubated and anesthesia is maintained on $1.5 \%$ to $3.0 \%$ isoflurane balanced in $\mathrm{O}_{2}$ throughout the surgery. An incision in the abdomen was made and the uterus exposed. Uterine arteries were isolated and removed without stretching, and placed into a cold physiological salt solution (PSS) containing (in $\mathrm{mM}$ ): $130 \mathrm{NaCl}, 10.0$ HEPES, 6.0 Glucose, $4.0 \mathrm{KCl}, 4.0 \mathrm{NaHCO}_{3}, 1.80 \mathrm{CaCl}_{2}$, $1.2 \mathrm{MgSO}_{4}, 1.18 \mathrm{KH}_{2} \mathrm{PO}_{4}$, and 0.025 EDTA, pH 7.4. After removal of the tissues, animals were killed with T-61 (euthanasia solution, Hoechst-Roussel, Somerville, NJ).

\section{Relaxation studies}

The fourth generation branches of the main uterine artery from pregnant sheep were separated from the surrounding tissue, and cut into 2-mm ring segments. For ex vivo treatment, the uterine arterial segments were incubated in phenol red-free DMEM with $1 \%$ charcoal-stripped FBS for 48 hours at $37^{\circ} \mathrm{C}$ in both normoxic chamber with $21 \% \mathrm{O}_{2}$ and hypoxia chamber with $10.5 \% \mathrm{O}_{2}$. Isometric tension was measured in the Krebs solution in a tissue bath at $37^{\circ} \mathrm{C}$, as described previously [18]. Briefly, each ring was equilibrated for 60 minutes and then gradually stretched to the optimal resting tension, as determined by the tension that developed in response to $120 \mathrm{mmol} / \mathrm{L} \mathrm{KCl}$ added at each stretch level. Our previous studies have demonstrated that activation of both large-conductance $\mathrm{Ca}^{2+}$-activated $\mathrm{K}^{+}$channels (BK) and small-conductance $\mathrm{Ca}^{2+}$-activated $\mathrm{K}^{+}$channels (SK) can cause uterine arterial relaxation.3,18 To see whether PKC regulates BK and SK-mediated relaxation, the arterial rings were pre-contracted with submaximal concentrations of norepinephrine, followed by additions of BK opener NS1619 or SK opener NS309 in the absence or presence of phorbol 12,13-dibutyrate (PDBu, PKC activator), added in a cumulative manner.

\section{Contraction studies}

The fourth generation branches of the main uterine artery from both pregnant and nonpregnant sheep were isolated, and cut into 2-mm ring segments and mounted in $10 \mathrm{~mL}$ tissue baths containing modified Krebs solution equilibrated with a mixture of $95 \%$ 
$\mathrm{O}_{2}$ and $5 \% \mathrm{CO}_{2}$. To see whether PKC and adrenergic receptor-mediated contractions were regulated by $\mathrm{BK}$ and SK, PDBu and norepinephrine-induced isometric tensions were determined in the absence or presence of BK inhibitor iberoitoxin (IBTX; $100 \mathrm{nmol} / \mathrm{L}$ ), tetraethylammonium (TEA; $1 \mathrm{mmol} / \mathrm{L}$ ) or SK blocker apamin $(500 \mathrm{nmol} / \mathrm{L})$, as described previous [23-25].

\section{Data analysis}

Concentration-response curves were analyzed by computer-assisted nonlinear regression to fit the data using GraphPad Prism (GraphPad Software, San Diego, CA). Results were expressed as means \pm SEM obtained from the number of experimental animals given. Differences were evaluated for statistical significance $(\mathrm{P}<0.05)$ by ANOVA or $t$ test, where appropriate.

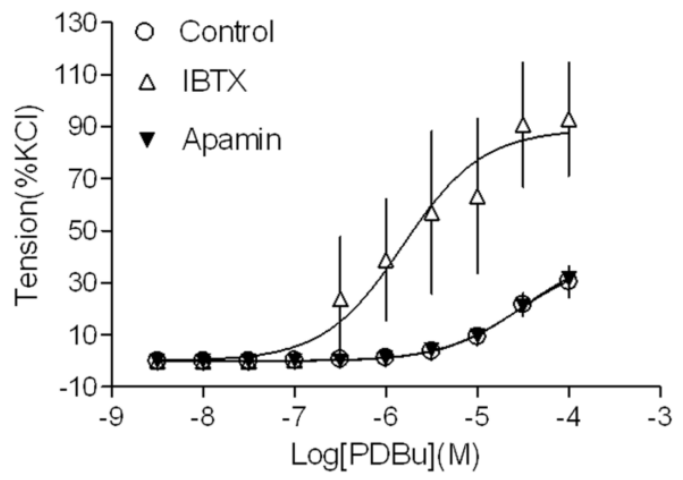

Figure I. Effect of $\mathrm{K}_{\mathrm{ca}}$ channel blockers on PDBu-induced contractions of uterine arteries from normoxic pregnant sheep. PDBu-induced contractions were determined in uterine arteries obtained from normoxic pregnant sheep in the absence (control) or presence of $100 \mathrm{nM}$ IBTX or $500 \mathrm{nM}$ apamin pretreatment for $20 \mathrm{~min}$. Data are means \pm SEM of tissues from 4-5 animals in each group.

\section{Results}

\section{Inhibition of BK channels increased PKC-mediated contractions}

Our recent studies have demonstrated that both BK and SK channels are expressed in uterine arterial smooth muscle cells $[3,15,18]$. In the present study, we investigated whether both types of $\mathrm{K}_{\mathrm{Ca}}$ channels played a role in regulating PKC-mediated uterine vascular contractility. As shown in Figure 1, inhibition of BK channels with IBTX significantly potentiated PKC activator PDBu-induced contractions in uterine arteries of pregnant animals ( $\mathrm{pD}_{2}$ values: $4.5 \pm 0.2$ in control group vs. $5.8 \pm 0.3$ in IBTX-treated group; $\mathrm{P}<$ 0.05 ; $\mathrm{E}_{\max }: 39.7 \pm 5.8 \%$ in control vs. $88.9 \pm 13.1 \%$ in IBTX-treated groups; P < 0.05). In contrast, inhibition of SK channels with apamin did not affect PDBu-induced contractions ( $\mathrm{pD}_{2}: 4.5 \pm 0.2$ vs. $4.5 \pm 0.1$; $\mathrm{P}>0.05 ; \mathrm{E}_{\max }: 39.7 \pm 5.8$ \% vs. $41.7 \pm 4.9 \%$; P > 0.05). The data suggest that BK, but not SK channels play an important role in inhibiting PKC-mediated uterine vascular contractions in pregnancy.

\section{Gestational hypoxia abrogated inhibitory effect of BK on PKC-mediated contractions}

In agreement with the previous findings that chronic hypoxia enhanced PKC-mediated uterine vascular contractions during pregnancy $[1,21,22]$, PDBu-induced contractions of uterine arteries of pregnant sheep were significantly greater in hypoxic animals ( $\mathrm{E}_{\max }: 83.8 \pm 5.4 \%$ ) (Figure $\left.2 \mathrm{~B}\right)$ than those in normoxic animals ( $\left.\mathrm{E}_{\max }: 38.5 \pm 1.8 \%\right)$ (Figure $\left.2 \mathrm{~A}\right)(\mathrm{P}<$ 0.05). Inhibition of BK channels with TEA (Figure 2A) significantly enhanced PDBu-induced contractions of uterine arteries in pregnant sheep of normoxic animals ( $\mathrm{E}_{\max }: 69.1 \pm 2.1 \%$ vs $38.5 \pm 1.8 \%$, P < 0.05). In contrast, inhibition of BK channels (Figure 2B) had no significant effect on PDBu-induced contractions of uterine arteries in pregnant sheep of hypoxic animals (Emax: $83.8 \pm 5.4 \%$ in control group vs. $76.9 \pm 12.5 \%$ in TEA-treated groups; $P>0.05)$. In the presence of TEA, there was no significant difference in PDBu-induced contractions between normoxic control ( $\mathrm{E}_{\max }$ : $69.1 \pm$ $2.1 \%$ ) and hypoxic ( $\mathrm{E}_{\max }: 76.9 \pm 12.5 \%$ ) animals (Figure 2). As shown in Figure 3, in uterine arteries of nonpregnant sheep, BK channel inhibition significantly enhanced PDBu-induced contractions in both normoxic (Figure 3A) and hypoxic (Figure 3B) animals. These data suggest that the inhibitory effect of BK channels on PKC-mediated contractions is selectively abrogated in uterine arteries of pregnant, but not nonpregnant animals acclimatized to long-term high altitude hypoxia.

\section{Chronic hypoxia induced PKC-mediated inhibition of $K_{\mathrm{Ca}_{\mathrm{a}}}$ channel activity}

As shown in Figure 4 and 5, both BK channel opener, NS1619 and SK channel opener, NS309 caused concentration-dependent relaxations of uterine arteries from pregnant animals. PDBu had no significantly effect on either NS1619- or NS309-induced relaxations under the normoxic condition (Figure 4A and $5 \mathrm{~A}$ ). Treatment of tissues with chronic hypoxia $\left(10.5 \% \mathrm{O}_{2}\right.$ for $48 \mathrm{~h}$ ) (Figure $\left.4 \mathrm{~B}\right)$ significantly reduced NS1619-induced relaxations as compared with normoxic control $\left(21 \% \mathrm{O}_{2}\right.$ for $\left.48 \mathrm{~h}\right)$ (Figure $\left.4 \mathrm{~A}\right)\left(\mathrm{E}_{\max }\right.$ : $19.9 \pm 1.1$ vs. $30.6 \pm 2.2 ; \mathrm{P}<0.05)$. Similar to NS1619, NS309-induced relaxations were also significant differences between the normoxic $\left(21 \% \mathrm{O}_{2}\right)$ (Figure $5 \mathrm{~A}$ ) and hypoxic $\left(10.5 \% \mathrm{O}_{2}\right)$ (Figure $\left.5 \mathrm{~B}\right)$ treatment $\left(\mathrm{E}_{\max }\right.$ : $18.9 \pm 1.8$ vs. $26.5 \pm 1.6$; $\mathrm{P}<0.05)$. In addition, under the hypoxic condition, PDBu significantly inhibited both NS1619- and NS309-induced uterine arterial relaxations (Figure 4B and 5B). 
A

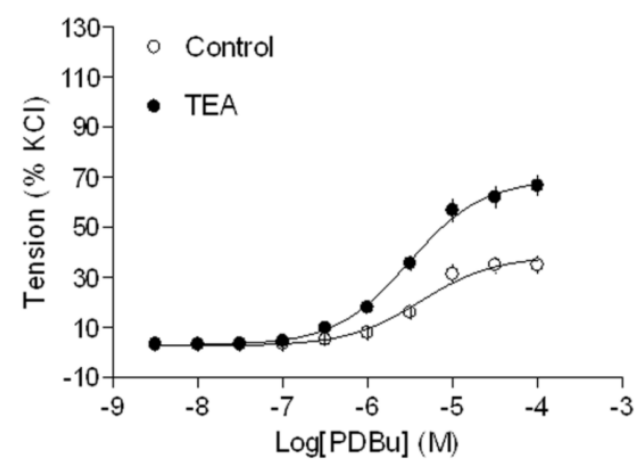

B

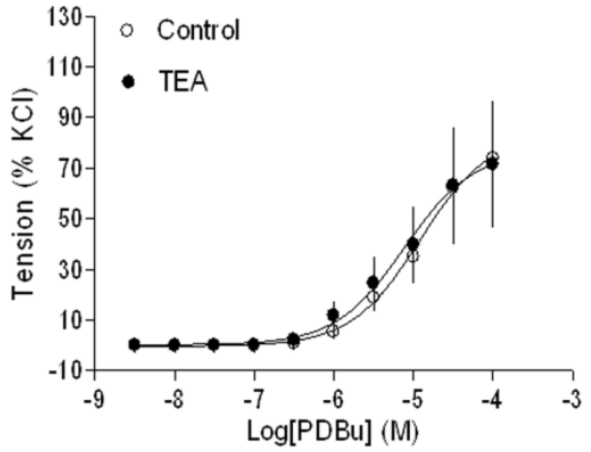

Figure 2. Effect of BK blocker on PDBu-induced contractions of uterine arteries from normoxic and hypoxic pregnant sheep. PDBu-induced contractions were determined in uterine arteries obtained from nomoxic (panel A) and hypoxic (panel B) pregnant sheep in the absence (control) or presence of I mM TEA pretreatment for $20 \mathrm{~min}$. Data are means \pm SEM of tissues from 4 animals in each group.
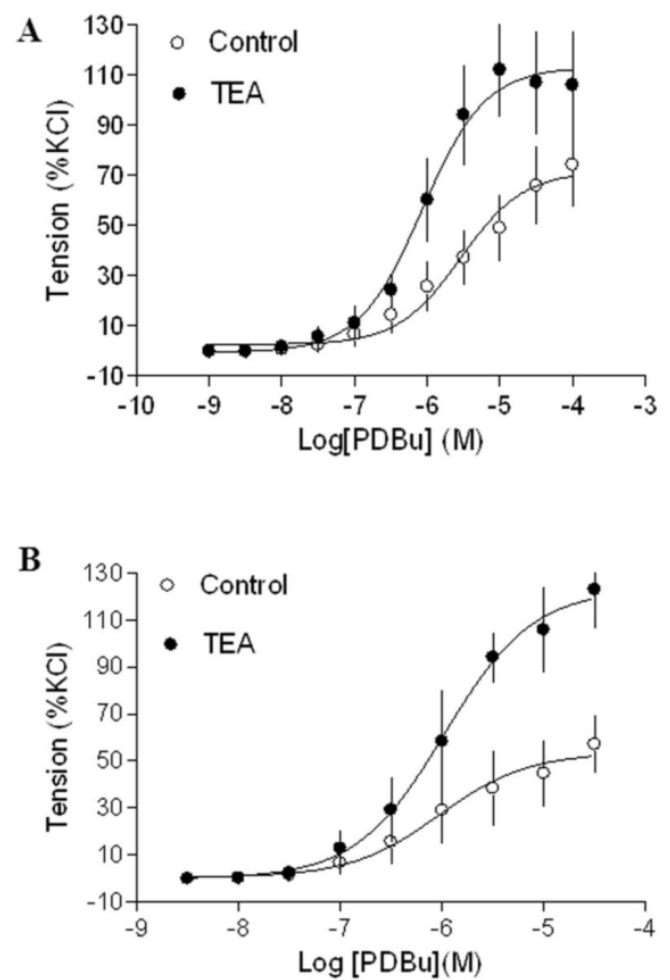

Figure 3. Effect of BK blocker on PDBu-induced contractions of uterine arteries from nonpregnant sheep. PDBu-induced contractions were determined in uterine arteries obtained from normoxic (panel A) and hypoxic (panel B) nonpregnant sheep in the absence (control) or presence of I mM TEA pretreatment for $20 \mathrm{~min}$. Data are means \pm SEM of tissues from 4-5 animals in each group.
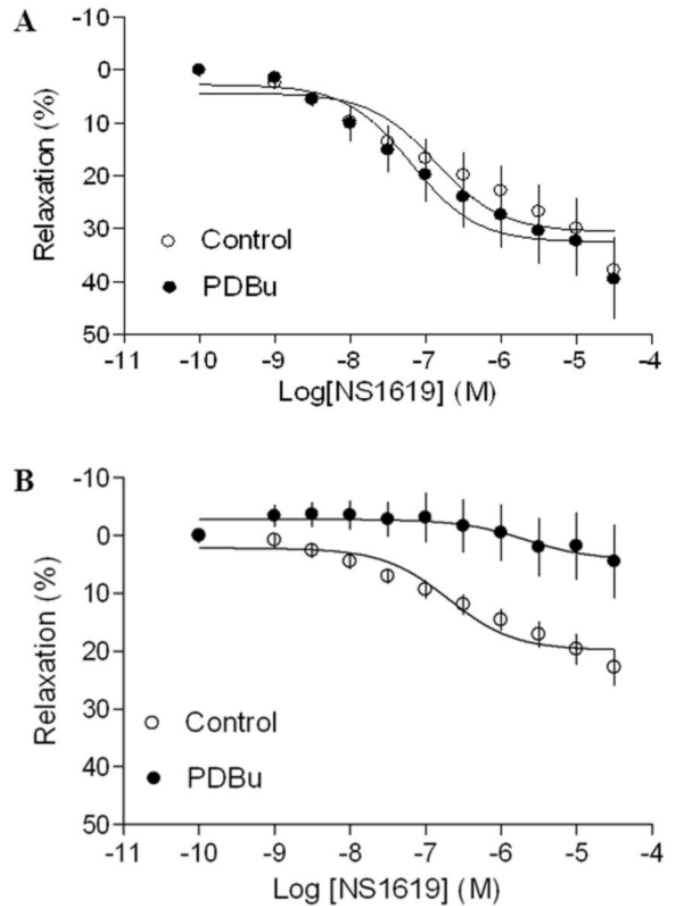

Figure 4. Effect of PDBu on BK opener-induced relaxations of uterine arteries from pregnant sheep. Uterine arteries were isolated from pregnant sheep and incubated under $21 \% \mathrm{O}_{2}$ or $10.5 \% \mathrm{O}_{2}$ for 48 h. BK opener NSI619 -induced relaxations of uterine arteries under normoxic (panel $\mathbf{A}$ ) and hypoxic (panel B) treatments were determined in uterine arteries pre-contracted with norepinephrine $(\mathrm{I} \mu \mathrm{M})$, in the absence (control) or presence of I $\mu \mathrm{M}$ PDBu. Data are means \pm SEM of tissues from 8-9 animals in each group.
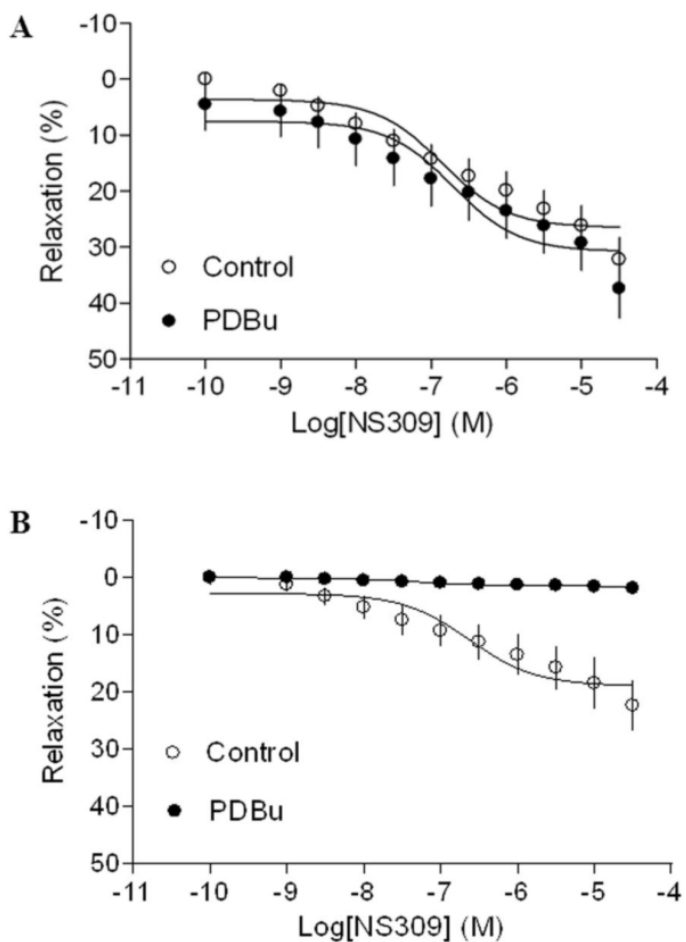

Figure 5. Effect of PDBu on SK opener-induced relaxations of uterine arteries from pregnant sheep. Uterine arteries were isolated from pregnant sheep and incubated under $21 \% \mathrm{O}_{2}$ or $10.5 \% \mathrm{O}_{2}$ for $48 \mathrm{~h}$. SK opener NS309-induced relaxations of uterine arteries under normoxic (panel A) and hypoxic (panel B) treatment were determined in uterine arteries pre-contracted with norepinephrine $(\mathrm{I} \mu \mathrm{M})$, in the absence (control) or presence of I $\mu \mathrm{M}$ PDBu. Data are means $\pm \mathrm{SEM}$ of tissues from 5-8 animals in each group. 


\section{A NNPUA}

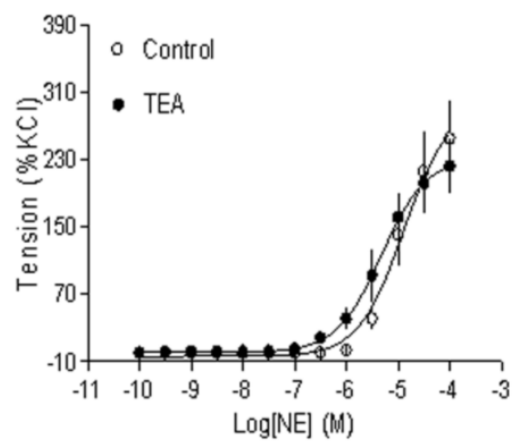

C NPUA

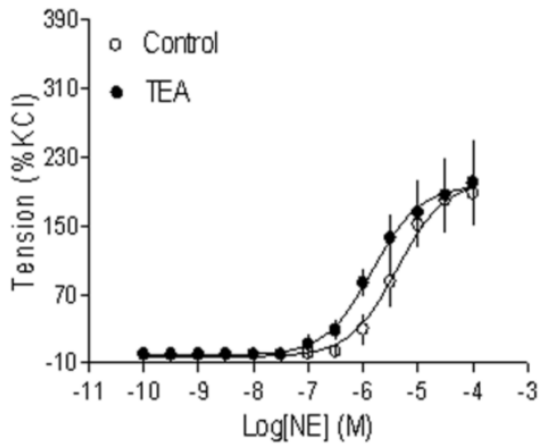

B HNPUA

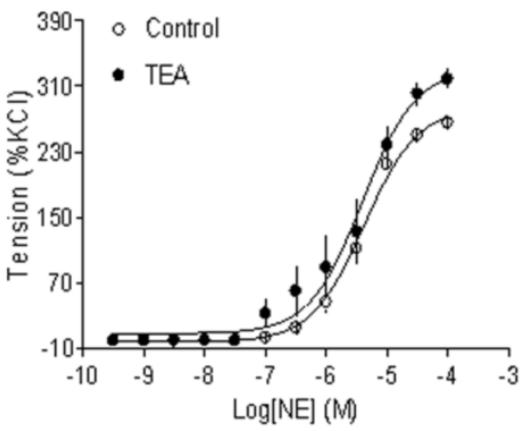

D HPUA

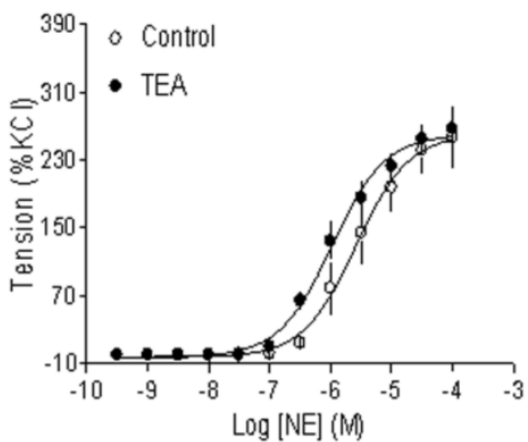

Figure 6. Effect of BK blocker on norepinephrine (NE)-induced contractions of uterine arteries. NE-induced contractions were determined in uterine arteries obtained from normoxic nonpregnant (panel A), hypoxic nonpregnant (panel B), normoxic pregnant (panel C) and hypoxic pregnant (panel D) sheep in the absence (control) or presence of I mM TEA pretreatment for 20 min. Data are means \pm SEM of tissues from 4-5 animals in each group.

\section{Inhibition of BK channels had no effect on norepinephrine-induced contractions}

To determine the specific interaction of BK channels and PKC-mediated contractions in uterine arteries, the effect of BK channel inhibition on $\alpha$-adrenoceptor-mediated contractions were examined. As shown in Figure 6, inhibition of BK channels had no significant effects on norepinephrine-induced contractions of uterine arteries from nonpregnant or pregnant sheep under either normoxic or hypoxic conditions.

\section{Discussion}

Our previous studies have demonstrated that both PKC and $\mathrm{K}_{\mathrm{Ca}}$ channels play an important role in uterine vascular adaptation to pregnancy and chronic hypoxia $[1,3,15,18,21,22,26]$. The present study provides new evidence that PKC and $\mathrm{K}_{\mathrm{Ca}}$ channels interact and integrate to regulate uterine vascular contractility under physiological and pathophysiological conditions. The major findings of the present study are the followings: 1) inhibition of BK but not SK channels potentiated PKC-mediated contractions of uterine arteries; 2) chronic hypoxia abrogated the inhibitory effect of BK channels on PKC-induced contractions of uterine arteries from pregnant, but not nonpregnant animals; 3) in uterine arteries of pregnant animals activation of PKC had no significant effects on either BK- or SK-mediated relaxations under the normoxic condition, but significantly inhibited them under the hypoxic condition; 4) inhibition of BK channels had no significant effects on $\alpha$-adrenoceptormediated uterine arterial contractions.

The present finding that inhibition of BK but not SK channels significantly enhanced PDBu-induced contractions suggests that the basal BK channel activity plays a significant role in counteracting PKC-mediated myogenic tone of uterine arteries. BK channels are important in the regulation of resting membrane potential and control of vascular tone $[15,17]$. Previous studies demonstrated that PKC played a key role in pressure-dependent myogenic response of uterine arteries [1], and inhibition of BK channels significantly increased pressure-dependent myogenic tone in uterine arteries of pregnant sheep [15]. This is consistent with the findings that intra-arterial infusion of BK channel inhibitor TEA into 
the uterine artery circulation of late-gestation sheep caused a significant decrease of basal uterine blood flow from $50 \%$ to $80 \%$ in the absence of systemic effects or a change in contralateral uterine blood flow $[16,17]$. We have demonstrated that TEA and IBTX inhibit the BK channel currents by the same extent of $53 \%$ in uterine arterial myocytes [15].

Of importance, chronic hypoxia during gestation abrogated inhibitory effect of BK channels on PKC-mediated contractions of uterine arteries, suggesting that loss of negative regulatory component of basal BK channel activity may be a key signaling mechanism in chronic hypoxia-mediated increase in PKC-induced myogenic contractions of uterine arteries in pregnancy, as demonstrated in the present study as well as the previous studies $[1,26]$. This notion is supported by our recent findings that gestational hypoxia down-regulated BK channel $\beta 1$ subunit gene expression and BK channel activity in uterine arteries [3]. Of interest, this hypoxic-mediated effect is pregnancy-dependent, as inhibition of BK channels enhanced PDBu-induced contractions of uterine arteries of nonpregnant sheep in both normoxic and hypoxic animals. Previous studies demonstrated that pregnancy up-regulated BK channel function in uterine arteries via the action of $17 \beta$-estradiol [15]. Further studies showed that chronic hypoxia during gestation caused heightened promoter methylation and resultant estrogen receptor- $\alpha(E R \alpha)$ gene repression in uterine arteries [27]. Taken together, these findings suggest a specific vulnerability of steroid hormone-mediated response in uterine vascular adaptation in pregnancy to gestational hypoxia.

In addition to that basal BK channel activity may be important in regulating PKC-mediated contractions of uterine arteries, several studies have shown a regulatory role of $\mathrm{PKC}$ on $\mathrm{K}_{\mathrm{Ca}}$ channel activation [28-30]. Our previous study showed that activation of PKC inhibited basal BK channel current density in uterine arteries [15]. In the present study, we found that both BK channel opener NS1619- and SK channel opener NS309-induced relaxations of uterine arteries were not altered by the PDBu treatment. This finding is intriguing and suggests different regulatory mechanisms of basal and activated $\mathrm{K}_{\mathrm{Ca}}$ channel activities in the uterine artery. Of importance, chronic hypoxia treatment induced PKC-mediated inhibition of NS1619- and NS309-produced relaxations. Our previous studies demonstrated that chronic hypoxia significantly increased the PKC activity in uterine arteries of pregnant sheep [1], suggesting a key role of hypoxia-mediated up-regulation of PKC activity in inhibiting BK and SK channel-mediated relaxations of uterine arteries in pregnancy. Although the mechanisms of hypoxia-induced up-regulation of inhibitory effect of PKC on activated $\mathrm{K}_{\mathrm{Ca}}$ channel activities remain to be determined, a selective increase in the activity of $\mathrm{PKC} \varepsilon$ isoform in uterine arteries by chronic hypoxia [1] may play a role. Indeed, activation of PKC $\varepsilon$ causes a stimulation of L-type $\mathrm{Ca}^{2+}$ channel through c-SRC, resulting in inhibition of $\mathrm{K}_{\mathrm{Ca}}$ channel activity [31]. There are more than twelve PKC isoforms in vasculature. Each of them may act differently in regulating vascular contractility. In present study, we only employed a pan-PKC activator $(\mathrm{PDBu})$. Therefore, isoform-specific activators or inhibitors might be needed to define the specific role of each PKC isoform in regulation of uterine vascular reactivity in future studies. Previous studies have demonstrated that PKC plays an important role in human uterine contractility at pathophysiological condition [32-34]. Jofre et al [32] showed a key role of PKC $\alpha$ in the maintenance of normal pregnancy myometrial quiescence in humans. Furthermore, they observed a reduction in the degree of PKC $\alpha$ activation in the samples obtained after the premature onset of labor, suggesting that an anticipated reduction in PKC $\alpha$ activity may be etiologically related to preterm labor.

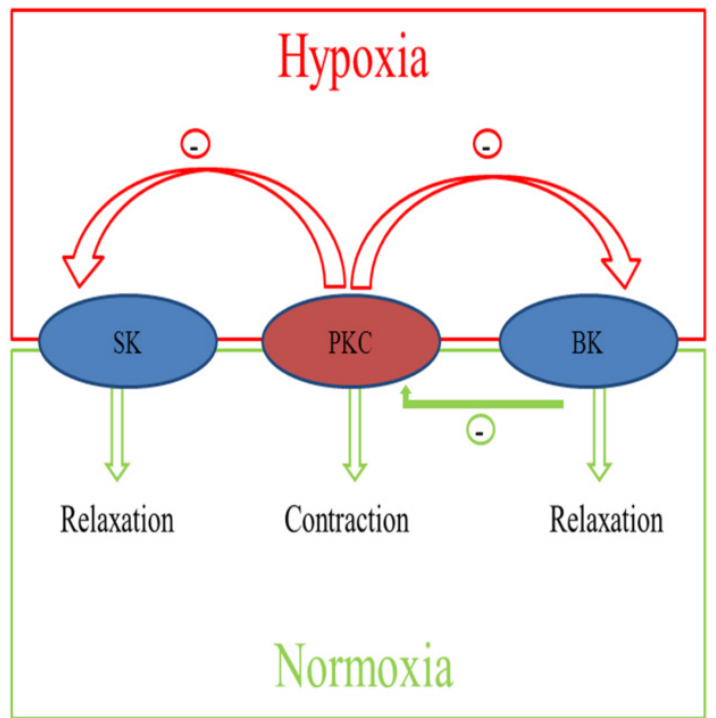

Figure 7. Diagram of the integrated effects of pregnancy and chronic hypoxia on the interactions of PKC and $K_{\mathrm{Ca}}$ channels in modulating uterine arterial contractility. The diagram shows that under the normoxic condition, heightened basal BK channel activity in pregnant animals has a negative regulatory effect on PKC-induced contraction and myogenic tone of the uterine artery. Chronic hypoxia during gestation down-regulates basal BK channel activity and abrogates its inhibition of PKC-mediated myogenic response. In addition, chronic hypoxia induces an inhibitory effect of PKC on activated $\mathrm{K}_{\mathrm{Ca}_{2}}$ channel-mediated relaxations of the uterine arteries in pregnant animals.

Taken together, as shown in Figure 7, pregnancy and chronic hypoxia differentially regulate the interaction of PKC and $\mathrm{K}_{\mathrm{Ca}}$ channels in modulating uterine arterial contractility. Thus, under the normoxic condition, heightened basal BK channel activity in preg- 
nant animals has a negative regulatory effect on PKC-induced contraction and myogenic tone of the uterine artery. Chronic hypoxia during gestation down-regulates basal BK channel activity and abrogates its inhibition of PKC-mediated myogenic response. In addition, chronic hypoxia induces an inhibitory effect of PKC on activated $\mathrm{K}_{\mathrm{Ca}}$ channel-mediated relaxations of the uterine arteries in pregnant animals. Collectively, these findings demonstrate complex yet integrated effects of pregnancy and chronic hypoxia on the interaction of PKC and $\mathrm{K}_{\mathrm{Ca}}$ channel activities in the uterine artery, which are important in normal adaptation of reduced uterine vascular tone in pregnancy as well as in maladaptation of increased uterine vascular contractility in response to chronic hypoxia in gestation.

\section{Acknowledgement}

This work was supported by National Institutes of Health Grants HL110125 (LZ), HL089012 (LZ), HD031226 (LZ), DA032510 (DX), and by the Regents of the University of California TRDRP grant 22XT-0022 (to D. Xiao).

\section{Competing Interests}

The authors have declared that no competing interest exists.

\section{References}

1. Chang K, Xiao D, Huang X, Longo LD, Zhang L. Chronic hypoxia increases pressure-dependent myogenic tone of the uterine artery in pregnant sheep: role of ERK/PKC pathway. Am J Physiol Heart Circ Physiol 2009; 296:H1840-H1849.

2. Chang K, Xiao D, Huang X, Xue Z, Yang S, Longo LD, Zhang L. Chronic hypoxia inhibits sex steroid hormone-mediated attenuation of ovine uterine arterial myogenic tone in pregnancy. Hypertension 2010; 56:750-757.

3. Hu XQ, Xiao D, Zhu R, Huang X, Yang S, Wilson SM, Zhang L. Chronic hypoxia suppresses pregnancy-induced upregulation of large-conductance $\mathrm{Ca}^{2+}$-activated $\mathrm{K}^{+}$channel activity in uterine arteries. Hypertension 2012; 60:214-222.

4. Zamudio S, Palmer SK, Dahms TE, Berman JC, Young DA, Moore LG. Alterations in uteroplacental blood flow precede hypertension in preeclampsia at high altitude. J Appl Physiol 1995; 79:15-22.

5. Julian CG, Galan HL, Wilson MJ, Desilva W, Cioffi-Ragan D, Schwartz J, Moore LG. Lower uterine artery blood flow and higher endothelin relative to nitric oxide metabolite levels are associated with reductions in birth weight at high altitude. Am J Physiol Regul Integr Comp Physiol 2008; 295:R906-R915.

6. Keyes LE, Armaza JF, Niermeyer S, Vargas E, Young DA, Moore LG. Intrauterine growth restriction, preeclampsia, and intrauterine mortality at high altitude in Bolivia. Pediatr Res 2003; 54:20-25.

7. White MM, Zhang L. Effects of chronic hypoxia on maternal vasodilation and vascular reactivity in guinea pig and ovine pregnancy. High Alt Med Biol 2003; 4:157-169.

8. Zamudio S, Palmer SK, Droma T, Stamm E, Coffin C, Moore LG. Effect of altitude on uterine artery blood flow during normal pregnancy. J Appl Physiol 1995; 79:7-14.

9. Palmer SK, Moore LG, Young D, Cregger B, Berman JC, Zamudio S. Altered blood pressure course during normal pregnancy and increased preeclampsia at high altitude (3100 meters) in Colorado. Am J Obstet Gynecol 1999; 180:1161-1168

10. Khalil RA, Granger JP. Vascular mechanisms of increased arterial pressure in preeclampsia: lessons from animal models. Am J Physiol Regul Integr Comp Physiol 2002; 283:R29-R45.

11. George EM, Granger JP. Mechanisms and potential therapies for preeclampsia. Curr Hypertens Rep 2011; 13:269-275.

12. Moore LG, Young D, McCullough RE, Droma T, Zamudio S. Tibetan protection from intrauterine growth restriction (IUGR) and reproductive loss at high altitude. Am J Hum Biol 2001; 13:635-644.
13. Xiao D, Buchholz JN, Zhang L. Pregnancy attenuates uterine artery pressure-dependent vascular tone: role of PKC/ERK pathway. Am J Physiol Heart Circ Physiol 2006; 290:H2337-H2343.

14. Zhou I, Xiao D, Hu Y, Wang Z, Paradis A, Mata-Greenwood E, Zhang L. Gestational hypoxia induces preeclampsia-like symptoms via heightened endothelin-1 signaling in pregnant rats. Hypertension 2013; 62:599-607.

15. $\mathrm{Hu} X \mathrm{X}$, Xiao D, Zhu $\mathrm{R}$, Huang X, Yang S, Wilson S, Zhang L. Pregnancy upregulates large-conductance $\mathrm{Ca}(2+)$-activated $\mathrm{K}(+)$ channel activity and attenuates myogenic tone in uterine arteries. Hypertension 2011; 58:1132-1139.

16. Rosenfeld CR, Cornfield DN, Roy T. Ca(2+)-activated $\mathrm{K}(+)$ channels modulate basal and $\mathrm{E}(2)$ beta-induced rises in uterine blood flow in ovine pregnancy. Am J Physiol Heart Circ Physiol 2001; 281:H422-H431.

17. Rosenfeld CR, Roy T, DeSpain K, Cox BE. Large-conductance $\mathrm{Ca}^{2+}$-dependent $\mathrm{K}^{+}$channels regulate basal uteroplacental blood flow in ovine pregnancy. J Soc Gynecol Investig 2005; 12:402-408.

18. Zhu R, Hu XQ, Xiao D, Yang S, Wilson SM, Longo LD, Zhang L. Chronic hypoxia inhibits pregnancy-induced upregulation of $\mathrm{SK}_{\mathrm{Ca}}$ channel expression and function in uterine arteries. Hypertension 2013; 62:367-374.

19. Magness RR, Rosenfeld CR, Carr BR. Protein kinase $C$ in uterine and systemic arteries during ovarian cycle and pregnancy. Am J Physiol 1991; 260:E464-E470.

20. Farley DB, Ford SP. Evidence for declining extracellular calcium uptake and protein kinase $\mathrm{C}$ activity in uterine arterial smooth muscle during gestation in gilts. Biol Reprod 1992; 46:315-321.

21. Xiao D, Zhang L. ERK MAP kinases regulate smooth muscle contraction in ovine uterine artery: effect of pregnancy. Am J Physiol Heart Circ Physiol 2002; 282:H292-H300.

22. Xiao D, Zhang L. Adaptation of uterine artery thick- and thin-filament regulatory pathways to pregnancy. Am J Physiol Heart Circ Physiol 2005; 288:H142-H148.

23. Xiao $D$, Huang $X$, Longo $L D$, Zhang $L$ PKC regulates alpha (1)-adrenoceptor-mediated contractions and baseline $\mathrm{Ca}(2+)$ sensitivity in the uterine arteries of nonpregnant and pregnant sheep acclimatized to high altitude hypoxia. High Alt Med Biol 2010; 11:153-161.

24. Xiao D, Huang X, Yang S, Zhang L. Direct chronic effect of steroid hormones in attenuating uterine arterial myogenic tone: role of protein kinase c/ extracellular signal-regulated kinase $1 / 2$. Hypertension 2009; 54:352-358

25. Gauthier KM, Spitzbarth N, Edwards EM, Campbell WB. Apamin-sensitive $\mathrm{K}^{+}$ currents mediate arachidonic acid-induced relaxations of rabbit aorta. Hypertension 2004; 43:413-419.

26. Xiao D, Huang X, Zhang L. Chronic hypoxia differentially up-regulates protein kinase C-mediated ovine uterine arterial contraction via actin polymerization signaling in pregnancy. Biol Reprod 2012; 87:142.

27. Dasgupta C, Chen M, Zhang H, Yang S, Zhang L. Chronic hypoxia during gestation causes epigenetic repression of the estrogen receptor- $\alpha$ gene in ovine uterine arteries via heightened promoter methylation. Hypertension 2012; 60:697-704.

28. Taguchi K, Kaneko K, Kubo T. Protein kinase $\mathrm{C}$ modulates $\mathrm{Ca}^{2+}$-activated $\mathrm{K}^{+}$ channels in cultured rat mesenteric artery smooth muscle cells. Biol Pharm Bull 2000; 23:1450-1454.

29. Barman SA, Zhu S, White RE. Protein kinase $C$ inhibits $B K_{C a}$ channel activity in pulmonary arterial smooth muscle. Am J Physiol Lung Cell Mol Physiol 2004; 286:L149-L155

30. Del Carlo B, Pellegrini M, Pellegrino M. Modulation of $\mathrm{Ca}^{2+}$-activated $\mathrm{K}^{+}$ channels of human erythrocytes by endogenous protein kinase C. Biochim Biophys Acta 2003; 1612:107-116.

31. Alioua A, Mahajan A, Nishimaru K, Zarei MM, Stefani E, Toro L. Coupling of c-Src to large conductance voltage-and $\mathrm{Ca}^{2+}$-activated $\mathrm{K}^{+}$channels as a new mechanism of agonist-induced vasoconstriction. Proc Natl Acad Sci USA 2002; 99:14560-14565.

32. Jofre NM, Delpiano AM, Cuello MA, Poblete JA, Vargas PA, Carvajal JA. Isoform $\alpha$ of PKC may contribute to the maintenance of pregnancy myometrial quiescence in humans. Reprod Sci 2013; 20:69-77.

33. Breuiller-Fouche M. PKC isoforms in human uterine contractility. Whodunit? Am J Obstet Gynecol 2004; 191:1051-1052.

34. Eude-Le Parco I, Dallot E, Breuiller-Forche M. Protein Kinase C and human uterine contractility. BMC Pregnancy Childbirth 2007; 7:S11 